\title{
The Syndrome of Infantile-Onset Saccade Initiation Delay
}

\author{
Michael S. Salman, Kristin M. Ikeda
}

\begin{abstract}
Introduction: Infantile-onset saccade initiation delay (ISID), also known as congenital ocular motor apraxia, is characterized by the inability to initiate volitional horizontal saccades. Other abnormalities including developmental delay and ataxia have been reported. The frequency of these abnormalities is unknown. We performed a detailed review of the medical literature to quantify features of ISID. Methods: We searched the English medical literature for articles related to ISID from 1952 to 2010 . Whenever possible, patients were excluded if they had acquired SID, Joubert syndrome or neurodegenerative conditions. The minimum prevalence was calculated for each abnormality. Results: Sixty-six articles with information on 288 patients were included in the analysis. Head thrusts were reported in $84.7 \%$. Blinks without head thrusts were used to initiate saccades in $41 \%$. The fast phases of the optokinetic response and vestibulo-ocular reflex were impaired in $69.8 \%$ and $34.4 \%$ respectively. Smooth ocular pursuit was abnormal in $33 \%$. Global developmental delay occurred in $41.3 \%$, speech or language delay in $36.5 \%$, cognitive delay in $17 \%$, hypotonia in $35.8 \%$, motor delay in $48.6 \%$, and ataxia/clumsiness in $49.3 \%$ of patients. Neuroimaging was performed on 197 patients and was normal in $39.1 \%$. Abnormalities involved the cerebellum (24.9\%), cerebrum (15.7\%), other infratentorial structures (11.7\%), and corpus callosum (6.1\%). Conclusions: Infantile-onset saccade initiation delay is frequently associated with deficits in reflexive saccades and less frequently with impaired smooth ocular pursuit. Developmental delay, hypotonia, and ataxia occur frequently in ISID, suggesting more global brain impairment and not just a saccadic disorder.
\end{abstract}

RÉSUMÉ: Le syndrome infantile du retard d'initiation des saccades. Contexte : Le syndrome infantile du retard d'initiation des saccades (SIRIS), aussi connu sous le mon d'apraxie motrice oculaire congénitale, est caractérisé par une inhabilité à initier des saccades horizontales volontaires. D'autres anomalies telles un retard de développement et une ataxie ont également été rapportées. La fréquence de ces anomalies est inconnue. Nous avons effectué une revue détaillée de la littérature médicale pour quantifier les manifestations du SIRIS. Méthode : Nous avons recherché des articles sur le SIRIS publiés en anglais de 1952 à 2010. Quand il était possible de le faire, nous avons exclu les patients qui présentaient un SIRIS acquis, un syndrome de Joubert ou des problèmes neurodégénératifs. Une prévalence minimale a été calculée pour chaque anomalie. Résultats : Soixante-six articles contenant de l'information au sujet de 288 patients ont été inclus dans l'analyse. Un déplacement compensateur brusque de la tête a été rapporté chez $84,7 \%$ des patients et un clignotement des paupières sans déplacement brusque de la tête était utilisé pour initier des saccades chez $41 \%$. Les phases rapides de la réponse optokinétique était altérée chez $69,8 \%$ des patients et le réflexe vestibulo-oculaire était altéré chez $34,4 \%$. La poursuite oculaire lente était anormale chez 33\%. Un retard de développement global était présent chez 41,3\%, un retard de la parole ou du langage chez 36,5\%, un retard cognitif chez $17 \%$, de l'hypotonie chez $35,8 \%$, un retard moteur chez 48,6\% et de l'ataxie/de la maladresse chez 49,3\% des patients. La neuroimagerie était normale chez $39,1 \%$ des 197 patients chez qui elle avait été effectuée. Les anomalies observées affectaient le cervelet chez 24,9\%, le cerveau chez $15,7 \%$, d'autres structures sous-tentorielles chez $11,7 \%$ et le corps calleux chez 6,1\%.Conclusions : Le SIRIS est souvent associé à des déficits des saccades réflexes et moins fréquemment à un défaut de la poursuite oculaire lente. Un retard de développement, de l'hypotonie et de l'ataxie sont souvent observés dans le SIRIS, ce qui suggère qu'il existe une atteinte cérébrale plus globale, pas uniquement un trouble des saccades.

Can J Neurol Sci. 2013; 40: 235-240

Infantile-onset saccade initiation delay (ISID), also known as congenital ocular motor apraxia (COMA), is characterized by the inability to initiate horizontal saccades on command with preserved vertical eye movements and generally preserved smooth ocular pursuit. ${ }^{1,2}$ Random spontaneous saccades may be seen in some patients with ISID.

Although the term 'congenital ocular motor apraxia' is commonly used in the medical literature, it is inaccurate because there is no apraxia and thus the term ISID will be used in this study. ${ }^{3}$ Infants with ISID are typically healthy and classically present with characteristic head thrusts at approximately six months of age soon after they develop head control. Less commonly, they present with an inability to follow visual objects at around two months of age. The head thrust may be replaced by eye blinks as the child gets older. ${ }^{1}$
Eye movement recordings reveal prolonged horizontal saccadic latency (response time) and hypometric saccades with normal saccade velocity., ${ }^{4,5}$ Reflexive saccades, including the fast phases of the vestibulo-ocular reflex (VOR) and optokinetic response (OKR) may also be impaired.-6 Vertical saccade initiation delays have also been reported, but are uncommon..$^{7-11}$ The underlying etiology of ISID is not known.

From the Section of Pediatric Neurology (MSS), Children's Hospital, University of Manitoba, Winnipeg, Manitoba; Schulich School of Medicine and Dentistry (KMI), Western University, London, Ontario, Canada.

Received July 26, 2012. Final Revisions Submitted October 18, 2012 Correspondence to: Michael S. Salman, Section of Pediatric Neurology, Children's Hospital, AE 308, 820 Sherbrook Street, Winnipeg, Manitoba, R3A 1R9, Canada. Email: msalman@hsc.mb.ca. 
Infantile-onset saccade initiation delay has been associated with a wide range of neuroimaging abnormalities, developmental delay and ataxia., , $12-14$ This suggests more widespread neurological dysfunction that is not limited to the saccadic system. The most commonly reported neuroimaging abnormality is inferior cerebellar vermis hypoplasia; ;,4,6,12,14 however, neuroimaging may be normal. ${ }^{12}$ Clumsiness/ataxia and developmental abnormalities may occur in ISID including motor delay, speech or language delay, and cognitive delay.,12-14 Clinicians should therefore be aware of these important comorbidities in ISID and should look for them during the assessment of these children.

The frequency of these clinical and neuroimaging abnormalities is currently unknown. We carried out a detailed analysis of the medical literature of patients with ISID in order to determine the prevalence and spectrum of these abnormalities.

\section{Methods}

Search strategy and selection criteria: We searched the English medical literature using PubMed for articles relating to ISID using a comprehensive search strategy. All articles between 1952, when the disorder was first described, and the end of December 2010 were included for consideration. References of relevant articles were also hand searched.

Inclusion criteria were a diagnosis of 'congenital ocular motor apraxia'; clinical description consistent with the diagnosis of ISID, i.e. impaired saccade initiation and normal saccade velocity; adequate description of the eye movement examination including smooth pursuit and reflexive saccades; and/ or adequate description of development and motor coordination. Exclusion criteria were patients with acquired ocular motor apraxia and whenever possible patients with Joubert syndrome, ataxia telangiectasia, Gaucher's disease, ataxia-ocular motor apraxia types 1 and 2, Niemann-Pick disease, spino-cerebellar degeneration, and other neurodegenerative conditions. These conditions were excluded because the clinical features, pathology, and disease course are not typical of that described in patients with ISID. ${ }^{3}$ The presence of horizontal head thrusts was not a prerequisite for inclusion because patients with ISID without head thrusts have been described. Our aim was to describe the whole clinical spectrum of this disorder.

Both authors performed the search independently and compiled the results of searches following discussion. Article titles and abstracts were read to identify potential studies for inclusion. If an article seemed appropriate but had insufficient details on further review, it was subsequently excluded.

Data extraction: Once the papers were selected for inclusion, they were analyzed under four key areas: neuro-ophthalmological abnormalities, neuroimaging findings, development, and motor abnormalities. Demographic information was collected and included the number of cases reported in each study, age at diagnosis, gender, and familial cases (siblings, monozygotic twins, and parents/children). Neuro-ophthalmological findings analyzed included the presence and direction of head thrusts, use of eye blinks to initiate saccades, direction of eye movements during head thrusts, presence of spontaneous or random saccades, smooth ocular pursuit, response to the oculo-cephalic maneuver, VOR cancellation, the presence of VOR fast phases on spinning in patients with horizontal ISID, OKR, and other neuro-ophthalmological abnormalities. Neuroimaging findings were collected and analyzed based on the location of abnormality (cerebellum, other infratentorial regions, cerebrum, corpus callosum, basal ganglia, thalamus, and other). Developmental and motor outcomes assessed included global developmental delay, cognitive delay, reading difficulties, behavioral difficulties, speech or language delay, motor delay, tone and the presence of ataxia or clumsiness. In instances where the number or percentages of patients with abnormalities were not reported but the term 'most patients had an abnormality' was used, we conservatively assumed this to mean $80 \%$ of patients had the abnormality.

Some studies reported information on the same patients over multiple publications. These studies and the findings of these patients were combined where possible so that no patient was duplicated in the analysis.

Statistical analysis: The number and percentage of the reported abnormalities were calculated across all studies. However, several studies did not report all the findings of interest. We included this missing information in our calculations by including the total number of cases in the denominator so that the percentages of abnormal findings represented their minimum prevalence in patients with ISID. For comparison, we also reported the percentage of abnormalities based on the number of patients where the information was reported, i.e. the denominator included only the cases where specific findings were reported so that the percentages of abnormal findings represented an upper limit of their prevalence in patients with ISID.

Three patients with Joubert syndrome were reported only as part of a larger group of patients with typical ISID. We did not exclude them from the analysis because 45 other patients with typical ISID would have had to be removed from the analysis and potentially reduce the power of the study.

\section{RESULTS}

One hundred and five articles were identified for possible inclusion through PubMed searches. Fifty articles were found to be potentially suitable for inclusion. Hand searches of the references of these articles identified 17 additional articles for inclusion.

The 67 articles selected for potential analysis included a total of 383 patients. Fifty-eight patients were excluded because they had been previously reported, had inadequate information available or had a condition listed in the exclusion criteria. In one of the studies, ${ }^{1}$ two of five patient groups (groups two and three $[\mathrm{N}=35]$ ) were excluded from the analysis because they had conditions listed in our exclusion criteria. We also excluded one further study, ${ }^{15}$ since the magnetic resonance imaging (MRI) images of the two patients reported showed the molar tooth sign. This neuroradiological sign was described in the medical literature in patients with Joubert syndrome and related disorders several years after the study was published.

This provided a total of 288 patients for analysis. Within this group of 288 patients, three patients with Joubert syndrome were included since excluding them would remove an additional 45 patients with typical ISID. ${ }^{16,17}$ The effect of these three patients on the results of the analysis was thought to be negligible because they constituted about one percent of the total sample. 
Table 1: Demographic information of the study cohort illustrating the number of patients (\%) with ISID

\begin{tabular}{|c|c|c|}
\hline Details & $\begin{array}{l}\text { Number of } \\
\text { patients }(\%)\end{array}$ & $\begin{array}{l}\text { (\%) after excluding } \\
\text { unreported cases }\end{array}$ \\
\hline Total number of patients analyzed & $288(100)$ & NA \\
\hline \multirow{3}{*}{ Gender $\begin{array}{r}\text { Male } \\
\text { Female }\end{array}$} & $151(52.4)$ & $(57.2)$ \\
\hline & $113(39.2)$ & $(42.8)$ \\
\hline & $24(8.4)$ & \\
\hline Age range (m: months, y:years) & $2.5 m-38 y$ & NA \\
\hline Number of siblingships & $19(6.6)$ & NA \\
\hline Number of monozygotic twins & $4(1.4)$ & NA \\
\hline Number of parent-child pairs & $5(1.7)$ & NA \\
\hline \multicolumn{3}{|l|}{ Head thrusts: } \\
\hline Yes & $244(84.7)$ & $(92.8)$ \\
\hline No & $19(6.6)$ & $(7.2)$ \\
\hline NR & $25(8.7)$ & \\
\hline Direction of head thrusts: & 244 & NA \\
\hline Horizontal bidirectional only & $220(90.2)$ & \\
\hline Vertical bidirectional only & $5(2.1)$ & \\
\hline Both horizontal and vertical & $1(0.4)$ & \\
\hline Horizontal asymmetric & $7(2.9)$ & \\
\hline Vertical asymmetric & $1(0.4)$ & \\
\hline Rightwards only & $4(1.6)$ & \\
\hline Leftwards only & $1(0.4)$ & \\
\hline Either rightwards or leftwards & $1(0.4)$ & \\
\hline Upwards only & 0 & \\
\hline Downwards only & $4(1.6)$ & \\
\hline \multicolumn{3}{|l|}{$\begin{array}{l}\text { Blinks without head thrusts to } \\
\text { facilitate saccades: }\end{array}$} \\
\hline Yes & $118(41)$ & $(95.9)$ \\
\hline No & $5(1.7)$ & $(4.1)$ \\
\hline NR & $165(57.3)$ & \\
\hline Blinks during head thrusts: & 244 & \\
\hline 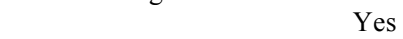 & $32(13.1)$ & $(86.5)$ \\
\hline No & $5(2.1)$ & $(13.5)$ \\
\hline \multirow[b]{2}{*}{$\begin{array}{l}\text { Direction of eye movements } \\
\text { during head thrusts: }\end{array}$} & $207(84.8)$ & \\
\hline & 244 & \\
\hline Opposite & $43(17.6)$ & $(87.8)$ \\
\hline Same & $3(1.2)$ & $(6.1)$ \\
\hline Either opposite or the same & $3(1.2)$ & $(6.1)$ \\
\hline NR & $195(80)$ & \\
\hline
\end{tabular}

NR: not reported, NA: not applicable

Details of the 66 studies, the information extracted, and their full references are available in the on-line electronic supplementary table.

The demographic details of the patients are shown in Table 1 . It was not possible to calculate the mean age at diagnosis since several studies reported only the mean age of their patients. The majority of patients; however, were infants or toddlers. In one unusual familial report, a 38-year-old father was found to have ISID in addition to his children (See reference 42 in the supplementary electronic table on-line for details).

Head thrusts were reported frequently and were mostly horizontal. Two patients displayed head turns rather than thrusts. Some patients had asymmetric or unidirectional head thrusts. Blinks occurred infrequently during head thrusts, although this finding was not reported in the majority of patients. Blinks without head thrusts were commonly observed. Some patients were described as displaying a lateral oblique gaze when fixating objects. ${ }^{2}$ We were not able to quantify this clinical feature in our study cohort because it was rarely mentioned.

Eye movements: Table 2 illustrates other eye movement features. Spontaneous or random saccades were reported infrequently. Smooth ocular pursuit was impaired or absent in at least $95(33 \%)$. Rarely, it was impaired both vertically and horizontally. The abnormality in smooth ocular pursuit was reported to improve in some patients with age. Smooth ocular pursuit may be normal on clinical examination but abnormal on eye movement recording. ${ }^{11}$ The response to the oculo-cephalic maneuver was documented infrequently and was normal in all patients in whom it was reported. The fast phases of the VOR on spinning were not reported in $183(63.5 \%)$ patients, a few of whom had only vertical ISID. This abnormality may be asymmetric or unilateral and may be present intermittently. It was reported to improve with age in two patients. ${ }^{13}$ Vestibuloocular reflex cancellation was rarely reported (14 patients), and was defective in all but one patient.

Many patients had impaired OKR fast phases (201, 69.8\%), (Table 2). The abnormality was described as horizontal, vertical, both or unidirectional. It may be intermittent or irregular. In contrast, the smooth phase of the OKR was impaired in five

Table 2: Neuro-ophthalmological findings $(\%)$ in patients with ISID

\begin{tabular}{|c|c|c|}
\hline Details & $\begin{array}{l}\text { Number of } \\
\text { patients (\%) }\end{array}$ & $\begin{array}{l}(\%) \text { after excluding } \\
\text { unreported cases }\end{array}$ \\
\hline \multicolumn{3}{|l|}{ Spontaneous or random saccades: } \\
\hline Yes & $56(19.4)$ & $(100)$ \\
\hline No & 0 & (0) \\
\hline NR & $232(80.6)$ & \\
\hline \multicolumn{3}{|l|}{ Smooth ocular pursuit: } \\
\hline Normal & 43 (14.9) & $(31.1)$ \\
\hline Impaired & $76(26.4)$ & $(55.1)$ \\
\hline Absent & $19(6.6)$ & $(13.8)$ \\
\hline NR & $150(52.1)$ & \\
\hline \multicolumn{3}{|l|}{ Response to oculocephalic maneuver: } \\
\hline Normal & $62(21.5)$ & $(100)$ \\
\hline Abnormal & 0 & (0) \\
\hline NR & $226(78.5)$ & \\
\hline \multicolumn{3}{|l|}{ VOR fast phases on spinning: } \\
\hline Normal & $6(2.1)$ & $(5.7)$ \\
\hline Abnormal & $51(17.7)$ & $(48.6)$ \\
\hline Absent & $48(16.7)$ & $(45.7)$ \\
\hline NR & $183(63.5)$ & \\
\hline \multicolumn{3}{|l|}{ VOR cancellation: } \\
\hline Normal & $1(0.3)$ & $(7.1)$ \\
\hline Defective & $13(4.5)$ & $(92.9)$ \\
\hline NR & $274(95.2)$ & \\
\hline \multicolumn{3}{|l|}{ OKR fast phases: } \\
\hline Present & $2(0.7)$ & (1) \\
\hline Impaired & $105(36.5)$ & $(51.7)$ \\
\hline Absent & $96(33.3)$ & $(47.3)$ \\
\hline NR & $85(29.5)$ & \\
\hline \multicolumn{3}{|l|}{ OKR smooth phases: } \\
\hline Present & $109(37.8)$ & $(81.4)$ \\
\hline Impaired & $5(1.7)$ & $(3.7)$ \\
\hline Absent & $20(7)$ & (14.9) \\
\hline NR & $154(53.5)$ & \\
\hline
\end{tabular}

NR: not reported 
Table 3: Other neuro-ophthalmological and neuroimaging findings $(\%) *$ in patients with ISID

\begin{tabular}{|c|c|c|}
\hline Details & $\begin{array}{l}\text { Number of } \\
\text { patients }(\%)\end{array}$ & $\begin{array}{l}\text { (\%) after excluding } \\
\text { unreported cases }\end{array}$ \\
\hline *Neuro-ophthalmological findings: & 68 & NA \\
\hline Nystagmus & $20(29.4)$ & \\
\hline Exotropia & $6(8.8) \dagger$ & \\
\hline Esotropia & $12(17.7) \dagger$ & \\
\hline Hypertropia & $2(3) \dagger$ & \\
\hline Other strabismus & $6(8.8) \dagger$ & \\
\hline All strabismus & $26(38.3) \dagger$ & \\
\hline Pigmented retina & $6(8.8)$ & \\
\hline Optic nerve abnormalities & $4(5.9)$ & \\
\hline §Other & $21(30.9)$ & \\
\hline *Type of neuroimaging: & 197 & \\
\hline CT, MRI, or both $\dagger$ & $181(91.9)$ & (94.8) \\
\hline Ultrasound & $5(2.5)$ & (2.6) \\
\hline Pneumoencephalography & $9(4.6)$ & (4.7) \\
\hline Arteriography & $3(1.5)$ & (1.6) \\
\hline $\mathrm{NR}$ & $6(3.1)$ & \\
\hline *Neuroimaging findings: & 197 & \\
\hline Normal & $77(39.1)$ & (43.8) \\
\hline Abnormalities in the cerebellum & $49(24.9)$ & (27.8) \\
\hline $\begin{array}{r}\text { Abnormalities in other infratentorial } \\
\text { structures }\end{array}$ & $23(11.7)$ & (13.1) \\
\hline Abnormalities in the corpus callosum & $12(6.1)$ & (6.8) \\
\hline Abnormalities in the thalamus & $9(4.6)$ & (5.1) \\
\hline Abnormalities in the basal ganglia & $5(2.5)$ & (2.8) \\
\hline Abnormalities in the cerebrum & $31(15.7)$ & (17.6) \\
\hline$\S$ General abnormalities & $6(3)$ & (3.4) \\
\hline $\mathrm{NR}$ & $21(10.7)$ & \\
\hline
\end{tabular}

NR: not reported, NA: not applicable, * Numbers and percentages may add up to $>100 \%$ since some patients had more than one investigation or finding, $\dagger$ estimate only due to incomplete description in the studies, $\S$ see supplementary e-table for details. $\mathrm{CT}=$ computed tomogram; MRI=magnetic resonance imaging

$(1.7 \%)$, absent in $20(7 \%)$, and was reported to normalize in some patients with age. However, it was not reported in 154 patients.

Other neuro-ophthalmological abnormalities: There were 68 patients with other neuro-ophthalmological abnormalities, with 77 abnormalities reported (Table 3). The most commonly reported abnormalities were strabismus and nystagmus. Rare findings included spasmus nutans, coloboma, Stargardt disease, and ocular flutter.

Neuroimaging abnormalities: Neuroimaging was reported on 197 patients, who had 204 imaging studies (Table 3). Magnetic resonance imaging was the most common imaging modality used. As anticipated, patients in the earlier studies were much less likely to have neuroimaging. Imaging findings were not reported in $21(10.7 \%)$ of the 197 patients. Of the remaining 176 patients, there were 212 findings. The most common finding was a normal neuroimaging study (77 patients). In one patient with normal neuroimaging, an autopsy revealed cerebellar cortical dysplasia. ${ }^{13}$ The most frequent abnormalities reported involved the cerebellum. The least frequent abnormalities were hydrocephalus and dilated ventricles. Some patients had multiple abnormalities on their neuroimaging. Details of the specific abnormalities can be found in the electronic supplementary table.
Development: Global developmental delay and speech/ language delay were reported relatively frequently while cognitive delay was noted infrequently (Table 4), but this latter finding was not reported in $167(58 \%)$. Reading ability was reported in 48 patients and reading difficulties were present in 26. Behavioral disturbances were not reported in most cases.

Motor development: Most patients had abnormal tone with 103 (35.8\%) being hypotonic (Table 4). Tone changed in one patient from hypotonia to hypertonia. ${ }^{7}$ Motor development was delayed in many cases, but improved significantly with age in some patients. Ataxia or clumsiness was present in 142 of the 223 patients in whom it was reported.

\section{Discussion}

Since its first description in 1952, ISID has become increasingly recognized as occurring with a wide range of other neuro-ophthalmological, motor and developmental findings. ${ }^{2,16,18}$ According to our conservative estimates, the frequency of these findings is suggestive of more widespread

Table 4: Neurological and developmental findings in patients with ISID

\begin{tabular}{|c|c|c|c|}
\hline Details & & $\begin{array}{l}\text { Number of } \\
\text { patients }(\%)\end{array}$ & $\begin{array}{l}(\%) \text { after excluding } \\
\text { unreported cases }\end{array}$ \\
\hline \multicolumn{4}{|l|}{ Tone: } \\
\hline & Normal & $50(17.4)$ & $(31)$ \\
\hline & Hypotonic & $103(35.8)$ & (64) \\
\hline & Hypertonic & $8(2.8)$ & $(5)$ \\
\hline & NR & $127(44.1)$ & \\
\hline \multicolumn{4}{|c|}{ Behavioral difficulties: } \\
\hline & Yes & $13(4.5)$ & $(22.4)$ \\
\hline & No & $45(15.6)$ & $(77.6)$ \\
\hline & NR & $230(79.9)$ & \\
\hline \multicolumn{4}{|c|}{ Developmental delay: } \\
\hline & Yes & $119(41.3)$ & $(66.1)$ \\
\hline & No & $61(21.2)$ & (33.9) \\
\hline & NR & $108(37.5)$ & \\
\hline \multicolumn{4}{|c|}{ Cognitive delay: } \\
\hline & Yes & $49(17)$ & $(40.5)$ \\
\hline & No & $72(25)$ & $(59.5)$ \\
\hline & NR & $167(58)$ & \\
\hline \multicolumn{4}{|c|}{ Speech and language delay: } \\
\hline & Yes & $105(36.5)$ & (59) \\
\hline & No & $73(25.3)$ & (41) \\
\hline & NR & $110(38.2)$ & \\
\hline \multicolumn{4}{|c|}{ Reading difficulties: } \\
\hline & Yes & $26(9)$ & $(54.2)$ \\
\hline & No & $22(7.6)$ & $(45.8)$ \\
\hline & NR & $240(83.4)$ & \\
\hline \multicolumn{4}{|c|}{ Motor delay: } \\
\hline & Yes & $140(48.6)$ & $(65.7)$ \\
\hline & No & $73(25.3)$ & $(34.3)$ \\
\hline & NR & $75(26.1)$ & \\
\hline \multicolumn{4}{|c|}{ Ataxia or clumsiness: } \\
\hline & Yes & $142(49.3)$ & $(63.7)$ \\
\hline & No & $81(28.1)$ & $(36.3)$ \\
\hline & NR & $65(22.6)$ & \\
\hline
\end{tabular}

NR: not reported 
brain dysfunction than is currently recognized clinically and on neuroimaging studies.

Given the fact that this condition is relatively uncommon, this investigation provides quantitative information on a large number of patients that would be difficult to ascertain by a single center. Our analysis confirms that ISID is frequently associated with many other neurological and developmental abnormalities and provides further insights into the nature of the eye movement abnormalities associated with this syndrome. However, as this study is a retrospective review of the published cases, it has predictable limitations. For example, several studies did not report all the findings of interest or used qualitative terms to describe the abnormalities found. Our study was primarily designed to give minimum prevalence estimates of the various abnormalities; therefore, their actual prevalence is likely higher. There have been numerous medical and neuroimaging advances since ISID was first described and, in the absence of a gold standard for the diagnosis of ISID, some of the patients included in the analysis may have another disorder.

We excluded patients with disorders that are associated with 'ocular motor apraxia', because detailed examination of eye movements in these disorders has revealed additional significant abnormalities other than increased saccadic latency that is characteristic of ISID. For example, decreased saccadic velocity is prominent in ataxia telangiectasia and Gaucher's disease, while severely hypometric saccades characterize ataxia-ocular motor apraxia types 1 and 2.,19,20 The multitude of developmental, neurological, and neuro-ophthalmological features reported in Joubert syndrome, including difficulty in initiating both horizontal and vertical saccades (which is atypical in ISID), saccadic dysmetria, impaired smooth ocular pursuit, nystagmus, strabismus, and impaired VOR responses, reflect the significant underlying brain malformation. ${ }^{21}$ The brain malformation in Joubert syndrome, typically involving the brainstem and cerebellum, causes static deficits which is incongruent with the improvement in tone and ataxia reported in patients with ISID.

Head thrusts are a common, but not universal finding in ISID. They may be absent despite the presence of adequate head control. ${ }^{19}$ Blinking is another common feature seen in patients with ISID and is used to initiate saccades; however, it was only reported in approximately half of the patients in our study. Many patients had defective OKR fast phases and VOR fast phases on spinning. This implies that the term 'apraxia' is used inappropriately to describe this condition because, in apraxia, reflexive saccades should be normal. ${ }^{3,22}$ Vassella first questioned the use of the term "apraxia" for this condition. ${ }^{23}$ In 1996, Harris et al. suggested that intermittent 'saccade failure' is a more appropriate term for the condition, because both volitional and reflexive saccades are commonly impaired. ${ }^{1}$ We have used the term "infantile-onset saccade initiation delay" because the abnormality is not apparent at birth and the delay reflects the prolonged saccadic latency in this disorder. ${ }^{3}$

Smooth ocular pursuit is often thought of as being normal in ISID, despite case reports to the contrary. In Cogan's original case series, he reported abnormalities of smooth pursuit in two of the four patients. ${ }^{24}$ Our analysis confirms that a large proportion of patients have abnormalities in smooth ocular pursuit and suggests that ISID is not solely a disorder of saccadic eye movements. This may be related to dysfunction in brain regions involved in processing both smooth ocular pursuit and saccades such as the cerebellum and frontal eye fields.

Vertical eye movements have generally been described as being unaffected in patients with typical ISID. In this analysis, vertical eye movement abnormalities remain an uncommon occurrence. We found few case reports in which vertical eye movements were the predominant problem..$^{711}$ In cases where horizontal eye movements are the main abnormality, subtle deficiencies in vertical eye movements have been described, though only one patient reported in this analysis had both vertical and horizontal abnormalities. ${ }^{9}$ These abnormalities are often only detected on formal eye movement recordings. The subtlety of these findings and limited use of eye movement recordings in ISID may underestimate the true prevalence of vertical eye movement abnormalities, and represents an area for future research.

Some of the additional features reported in some patients with ISID seem incongruous. For example, nystagmus was noted in 20 patients while intact VOR and OKR fast phases were noted less frequently. In addition, the proportion of patients with abnormal smooth ocular pursuit and abnormal smooth pursuit of the OKR were not similar. The number of unreported cases for each of these abnormalities was variable within and across the studies, which may account for the discrepancy.

Neuroimaging abnormalities are varied and may be subtle. They are most often found infratentorially in the inferior vermis of the cerebellum or in the region around the fourth ventricle. Less commonly, abnormalities in the corpus callosum, basal ganglia, thalamus and a variety of cerebral findings (e.g. microcephaly and grey matter heterotopias) are reported. The brain magnetic resonance imaging (MRI) is often normal. This large diversity in neuroimaging findings makes it difficult to provide a unifying mechanism that could explain this syndrome. We recently proposed that the saccadic abnormality seen in ISID may be caused by bilateral damage to analogous brain regions involved in processing saccades or by interruption of saccadic signals transfer along pathways that connect saccadic brain regions across the left and right sides of the brain. ${ }^{3}$ This hypothesis provides several possible localizations. Such abnormalities may be too small to see on routine MRI. The emergence of diffusion tensor imaging may provide a better way of further assessing this hypothesis.

Although developmental outcomes are not always reported, there is a clear association between delayed development and ISID in about $40 \%$ of the patients. The developmental delay is generally not severe. It can be global, or selectively involve motor skills, speech and language, cognition or reading. The frequency of these abnormalities points to a more widespread brain dysfunction in ISID than is currently appreciated.

Ataxia or clumsiness is one of the most frequent nonophthalmological findings reported in ISID and occurs in just under half the patients. This is not surprising because the most common abnormalities reported on neuroimaging involve the cerebellum or other posterior fossa structures.

The prognosis of the various deficits reported in ISID is reported to be favourable; however, definite and reliable evidence for this is lacking beyond very few case reports. A prospective study on the natural history of ISID is needed. 


\section{Conclusion}

Infantile-onset saccade initiation delay should be thought of as a neurological syndrome characterized by saccadic and other eye movement abnormalities, developmental delay, hypotonia and ataxia. It may be associated with cognitive and behavioral difficulties. Brain MRI may be normal or may reveal a diverse range of abnormalities, especially in the cerebellum. It will be important to further characterize the extent of the eye movement abnormalities with eye movement recordings. In addition, with the advent of higher resolution MRIs and diffusion tensor imaging, more subtle abnormalities may be detected. This may shed insight on the potential mechanisms and etiology of ISID.

\section{ACKNOWLEDGMENT}

The authors thank the reviewers for their insightful comments.

\section{REFERENCES}

1. Harris CM, Shawkat F, Russell-Eggitt I, Wilson J, Taylor D. Intermittent horizontal saccade failure ('ocular motor apraxia') in children. Br J Ophthalmol. 1996;80:151-8.

2. Kondo A, Saito Y, Floricel F, Maegaki Y, Ohno K. Congenital ocular motor apraxia: clinical and neuroradiological findings, and long-term intellectual prognosis. Brain Dev. 2007;29:431-8.

3. Salman MS, Ikeda KM. Disconnections in infantile-onset saccade initiation delay: A hypothesis. Can J Neurol Sci. 2010;37: 779-82.

4. Shawkat FS, Kingsley D, Kendall B, Russell-Eggitt I, Taylor DSI, Harris CM. Neuroradiological and eye movement correlates in children with intermittent saccade failure: "Ocular motor apraxia". Neuropediatrics. 1995;26:298-305.

5. Zee DS, Yee RD, Singer HS. Congenital ocular motor apraxia. Brain. 1977;100:581-99.

6. Harris CM, Hodgkins PR, Kriss A, et al. Familial congenital saccade initiation failure and isolated cerebellar vermis hypoplasia. Dev Med Child Neurol. 1998;40:775-9.

7. Anteby I, Lee B, Noetzel M, Tychsen L. Variants of congenital ocular motor apraxia: Associations with hydrocephalus, pontocerebellar tumor, and a deficit of vertical saccades. JAAPOS. 1997;1:201-8.

8. Ebner R, Lopez L, Ochoa S, Crovetto L. Vertical ocular motor apraxia. Neurology. 1990;40:712-3.

9. Garbutt S, Harris CM. Abnormal vertical optokinetic nystagmus in infants and children. Br. J Ophthalmol. 2000;84:451-5.

10. Ro A, Gummeson B, Orton RB, Cadera W. Vertical congenital ocular motor apraxia. Can J Ophthalmol. 1989;24:283-5.

11. Hughes JL, O'Connor PS, Larsen PD, Mumma JV. Congenital vertical ocular motor apraxia. J Clin Neuroophthalmol. 1985;5: 153-7.

12. Jan JE, Kearney S, Groenveld M, Sargent MA, Poskitt, KJ. Speech, cognition and imaging studies in congenital ocular motor apraxia. Dev Med Child Neurol. 1998;40:95-9.

13. Fielder AR, Gresty MA, Dodd KL, Mellor DH, Levene MI. Congenital ocular motor apraxia. Trans Ophthalmol Soc UK. 1986;105:589-98.

14. Kim JS, Park SH, Lee KW. Spasmus nutans and congenital ocular motor apraxia with cerebellar vermian hypoplasia. Arch Neurol. 2003;60:1621-4.

15. Whitsel EA, Castillo M, D'Cruz D. Cerebellar vermis and midbrain dysgenesis in oculomotor apraxia: MR findings. Am J Neuroradiol. 1995;16:831-4.

16. Marr JE, Green SH, Willshaw HE. Neurodevelopmental implications of ocular motor apraxia. Dev Med Child Neurol. 2005;47:815-9.

17. Sargent MA, Poskitt KJ, Jan JE. Congenital ocular motor apraxia: Imaging findings. Am J Neuroradiol. 1997;18:1915-22.

18. Grigorian AP, Fray KJ, Brodsky MC, Phillips PH. Neurodevelopmental outcomes with congenital ocular motor apraxia. Br J Ophthalmol. 2010;94:265-7.

19. Le Ber I, Bouslam N, Rivaud-Péchoux S, et al. Frequency and phenotypic spectrum of ataxia with oculomotor apraxia 2: a clinical and genetic study in 18 patients. Brain. 2004;127: 759-67.

20. Le Ber I, Moreira M, Rivaud-Péchoux S, et al. Cerebellar ataxia with oculomotor apraxia type 1: clinical and genetic studies. Brain. 2003;126:2761-72.

21. Tusa RJ, Hove MT. Ocular and oculomotor signs in Joubert syndrome. J Child Neurol. 1999;14(10):621-7.

22. Sharpe JA, Johnston JL. Ocular motor paresis versus apraxia. Ann Neurol. 1989;25:209-10.

23. Vassella F, Lutschg J, Mumenthaler M. Cogan's congenital ocular motor apraxia in two successive generations. Dev Med Child Neurol. 1972;14:788-803.

24. Cogan DG. A type of congenital ocular motor apraxia presenting jerky head movements. Trans Am Acad of Ophthalmol Otolaryngol. 1952;56:853-62. 